\title{
The Future of Community Health Services
}

\author{
MILTON TERRIS, M.D.
}

$\mathrm{T}$ IWEN'TY years ago, when I first entered the field of public health, I had the good fortune to become an apprentice epidemiologist in the New York State Department of Health. The epidemiologic tradition was very strong in New York at that time; our seniors preferred to be members of the epidemiology section rather than the health officers section of the American Public Health Association, and it was no accident that we were called apprentice epidemiologists rather than health officers-intraining.

Public health practice then was oriented to communicable disease epidemiology; among other duties as an apprentice health officer, I visited adults with chickenpox to make certain they did not have smallpox, investigated sporadic cases of typhoid fever and small outbreaks of food poisoning, assisted in immunization clinics, observed public health nurses teach families the care of communicable disease in the home, made contact investigations in syphilis, attempted to convince tuberculosis patients who were hazards to their families that they should accept hospitalization, and learned the intricacies of the syphilis and tuberculosis case registers. The main concerns of the health departments were water and milk sanitation, maternal and child health, and the control of communicable diseases, of which syphilis, tuberculosis, and poliomyelitis were the most important. There was a new program of cancer

Dr. Terris is head of the chronic disease unit, division of epidemiology, Public Health Research Institute of the City of New York, Inc. The paper is based on an address given at a series of regional conferences sponsored by the department of public health nursing of the National League for Nursing held in April 1962. control, but our contact with it at the local level was limited to occasional visits to physicians to obtain further information on cases for the cancer register.

Iuring my apprenticeship, I spent 1 month visiting the various divisions and bureaus in the central office in Albany. It was there I learned that a controversy had arisen in the department over the issue of whether public health nurses should do bedside nursing. It wasn't clear who had raised the issue, but apparently there was a great deal of resistance to such an extension of functions of public health nursing in official agencies. At any rate, nothing came of it; during the next few years that $I$ was with the department, I heard no further discussions of this question, and no bedside nursing programs were introduced.

As I look back upon that period, I am impressed with the absence of any sense of crisis or uncertainty. There was a lot of work to be done, protecting mothers and children and fighting major communicable diseases along established lines, and nobody, or hardly anybody, was asking that agonizing question which preoccupied the public health movement in the fifties: "Where are we going in public health?"

The past serenity of the public health movement has been shattered by a curious paradox. The fight against disease has resulted in an increase in disease, or, more exactly, the very successes of public health in preventing disease have created a population which suffers more disease than ever before. This seems inconceivable at first glance, a crude and monstrous joke which bears no relation to reality.

Nevertheless, it is true. Public health achieved brilliant successes in preventing infants from dying of diarrheal diseases, mothers from dying in childbirth, and children and 
young adults from dying of diphtheria, whooping cough, typhoid fever, and tuberculosis. As a result, people live longer, and more of them reach the ages at which illness rates are very high. For the population as a whole, the amount of morbidity now is considerably greater than in the days when the population was relatively young. Furthermore, the trend is a continuing one; unless measures to prevent the major diseases are discovered, the prospect is that the burden of disease and disability will rise inexorably.

This is the core of the crisis in public health. Our health services and facilities, conceived, organized, and constructed in the first few decades of this century, were well fitted to meet the urgent health problems of their day. Today they are antiquated and desperately inadequate. Having failed to heed the changes taking place in the character of the population and in the nature of its diseases, we have been content to follow traditional patterns of thinking and customary, comfortable methods of work. But the pressures created by these changes can no longer be ignored. Our generation must come to grips with the difficult task of reorienting, reorganizing, and rebuilding community health services to meet the critical health needs of the present day.

\section{The Present Situation}

The community health services which we have inherited are geared primarily to patients with acute disease. Nowhere is this more evident than in our hospital system. Patients who need long-term hospital care have no real place in our general hospitals; these are clearly designed to care for acute illness only, and the long-term patient is an unwelcome and uncomfortable guest. He is either discharged as soon as possible to his home, the county infirmary, or a nursing home, or, if no place can be found to accept him, he stays in the hospital, is more or less tolerated, more or less neglected, and more or less likely to receive from the house staff the callous designation of "old crock."

The acute general hospital is not organized to meet the needs of such a patient. Unlike the person who is acutely ill, he has become a resident of the hospital; he must live in it for weeks, or months, or even years. And "living" means having at least a closet for his belongings, not merely a tiny chest next to his bed; it means being in a hospital built to permit wheel chair traffic; it means sufficient nursing, medical social work, physical therapy, occupational therapy, and other rehabilitation services; it means recreational and educational opportunities; in short, it means treating the long-term patient as a human being who should be permitted to have as full a life as possible within the institutional setting.

The general hospital is, as presently conceived and operated, hardly the place to provide the warm, human, compassionate care which the long-term patient, and for that matter, the short-term patient, requires. The patient in a modern general hospital soon learns that he is in a rather sterile, aseptic, desiccated environment. His physician is truly a "visiting" physician who drops in to see him for a few minutes each day, and there is a succession of interns, residents, laboratory technicians, nurses, nurses' aides, and orderlies who examine him, inject him, give him pills, take his temperature, feed him, wake him from sleep, and so forth, all according to the routines of the hospital and often without regard for his needs and comfort. These people are busy, usually too busy to talk to the patient, find out what he's worrying about, quiet his fears, and reassure him. This is not entirely their fault; most of them have not been trained to do otherwise, and, even if they have, the hospital setting makes it difficult to escape the treadmill. For our hospitals have become an industry (hospital leaders even boast of how big and important an industry), and they have tended to adopt the factory system common to industry. This means that the job must be done with the least possible expenditure for labor, since labor costs, especially for skilled personnel such as nurses, are a major and expensive part of the budget. Even if all nurses were trained to give the kind of personal nursing care we like to talk about, the personnel ratios, geared to getting the basic routines done with the least possible staff, make it impossible. And the harried hospital administrator operates this way not, as in industry, with a view to increasing profits, but rather, since hospitals are so charily financed, to decrease the deficits. 
High-quality chronic hospital care is now provided in a few outstanding voluntary and local governmental institutions and, on a large scale, in the Veterans Administration hospital system. In the country as a whole, chronic hospital facilities, whether good or bad, are in short supply; they do not exist in many communities.

Nursing homes are plentiful in comparison. But the great majority of these are operated on a proprietary basis, and the level of care is generally so poor that it is no exaggeration to state that the condition of American nursing homes is a national disgrace. The Senate Subcommittee on Problems of the Aged and Aging, in its report of February 1960, outlined these major criticisms of the present level of nursing home care in the United States.

1. Physical plants and equipment are substandard and outmoded.

2. Home operators often lack proper qualifications to assure the provision of proper service.

3. Nursing personnel lack proper experience and training to supervise or to render skilled nursing care.

4. Types of services provided are too limited to meet the needs of patients.

5. Management of the patients in nursing homes by physicians is either lacking or inadequate.

6. Licensure standards differ greatly and are either too low or are not being enforced because of the practical problem of finding a place to put the patient.

7. Licensure agencies lack sufficient personnel to do really effective inspection and consultation even where standards exist.

8. The "storage-bin" philosophy still prevails in spirit or in fact in most nursing homes.

The report of the Senate subcommittee concludes: "This is the discouraging picture of nursing homes and their patients painted by knowledgeable people in the year 1959. One cannot see this picture as often as did the subcommittee without wondering for how many people - too well to die but too disabled to live independently or with their families-the future holds only needless relegation to such a limbo here on earth and whether that society which has created the situation has a responsibility for corrective action."
Modern rehabilitation services and facilities, despite strenuous promotion during the past two decades, are still limited largely to metropolitan centers; they are not to be found in most communities. Equally lacking, unfortunately, are coordinated home care programs which provide the spectrum of services required to care for the chronically ill at home: nursing, physical and occupational therapy, medical social work, X-ray and laboratory service, housekeeper service, transportation, sickroom equipment, and supplies and appliances. Although coordinated home care has received a great deal of favorable discussion and publicity, the mountains of words have produced molehills of community action. A few programs have been established by hospitals, visiting nurse associations, and health departments, but these are few and far between; coordinated home care does not exist in most American communities.

Rehabilitation and coordinated home care are essentially new programs, and the slow pace of their development can be explained, at least in part, by the difficulties attendant on novelty. Home nursing, on the other hand, is not new (the first District Nursing Association in the United States was established in Buffalo in 1885), and its patterns of organization and traditions of humane, devoted care have been developed over many years. Yet there are no visiting nurse associations in a majority of cities and towns with a population below 100,000 , and even in the larger cities where they do exist, the financial support does not always permit adequate coverage. The gaps might have been filled by local health departments, but they have so far been unable to develop the necessary services because of an excessive devotion to concepts and formulas of the past and the unwillingness of appropriating bodies to provide funds. As a result, a distressingly large number of communities in the United States have no home nursing services of any kind, while in many others the services available can meet only a fraction of the need.

\section{Personnel Needs}

A major factor in the present crisis of our health services has been the failure to understand the greatly increased requirements for 
personnel. The growth of the population has not been matched by a corresponding growth in numbers of professional health workers, so that we are in the precarious position of having fewer health workers per unit of population when we need more of them than ever before.

A number of social changes have brought increased demands for health service. The population has not only become older and sicker but also more urbanized and more educated. Prepayment, which hardly existed 30 years ago, has played an important part. The health services have also changed; they have become more complex and require a greater number and variety of professional: skills than previously. Finally, the health professions themselves have increased the need for personnel; when nurses succeeded in having the antediluvian 12-hour day relegated to the past, they raised the need for nurses by 50 percent. Even the medical profession, which still works a 12-hour day, shows signs of a growing willingness to join the rest of humanity and adopt a civilized workweek; as it gradually moves in this direction, it also increases the number of physicians required to serve the population.

There is every indication that the present shortages of physicians, dentists, nurses, medical social workers, laboratory and X-ray technicians, physical and occupational therapists, dietitians, medical record librarians, and other health personnel will become more critical each year. Unless health personnel needs are evaluated more realistically and rapid, effective action is undertaken, the lack of personnel will become a massive barrier thwarting all attempts to modernize community health services.

For example, at present, there are only 30,000 public health nurses in the United States, of whom about a third are school nurses unavailable for general community nursing. Applying the conservative estimate that 1 public health nurse per 2,000 persons is sufficient to provide complete public health nursing service, including bedside nursing care, the current requirement for the approximately 180 million population is 90,000 nurses. While it is true that some of this need may be met by registered nurses without public health training, by nurses combining family responsibilities with part-time employment, and by practical nurses, there is no question that a large increase in the numbers of available nursing personnel will be necessary. Without such an increase it will be manifestly impossible to meet the urgent needs for home nursing resulting from the growing burden of chronic illness.

Similar considerations apply to institutional nursing. When the badly needed facilities for chronic hospital and nursing home care are constructed, where will we find the nursing and other types of personnel to staff these facilities? We can afford to disregard this question only at our peril.

\section{Changing Characteristics}

The future of community health services can be outlined only in terms of the characteristics of disease in the population and the service requirements which derive logically from these characteristics. If, as all present data indicate, chronic disease and disability will be a dominant and growing part of the total picture, then the community health services of the future must be reorganized to take this fully into account.

Most chronic diseases which now plague us are not yet preventable. This does not mean that attention should therefore be turned entirely to medical care. On the contrary, what is required is a further development of research to discover the causes and prevention of heart disease, cancer, cerebral vascular disease, arthritis, diabetes, schizophrenia, and the other major chronic diseases. Health departments particularly must revive and greatly strengthen their epidemiologic traditions, with an orientation primarily to the chronic rather than the communicable diseases. Epidemiologic research in chronic disease needs to become a major activity of all State health departments. Unless ways can be found to prevent specific diseases, the perspective is for an inevitably increasing volume of chronic disease and disability as the population continues to age and an inevitably increasing need for more personnel and more facilities to care for the results of our failures in prevention.

When preventive measures are not yet available, community health services must be organized to discover chronic disease early so that 
medical care may be instituted in order to halt, insofar as possible, the progress of disease and disability. Periodic medical examinations, which have proved so successful in obstetrics and pediatrics, need to be extended to the adult population; they should become an integral part of the community health services of the present and the future. Multiphasic screening, cytologic examinations for malignancy, and "welladult clinies" are among the methods and approaches which will need to be explored and developed on a much wider scale than at present.

The individual who is chronically ill requires more than the episodic care which suffices for acute disease. He needs continuous supervision so that the medical skills and health services brought to bear on his disease are adequate and appropriate to the stage of illness. At one time he may need ambulatory care; at another, hospital care for an acute episode; at still another, chronic hospital care, nursing home service, coordinated home care, or rehabilitation.

Clearly the community health services must be organized to provide continuity of care and easy and efficient transfer from one type of service to another. This in turn requires that the individual be under the care of a general physician who is responsible for his continuing supervision and has readily arailable the services of a variety of specialized physicians. The growing trend to group practice reflects, at least in part, a greater awareness by the medical profession that close coordination of the services of general physicians and specialists is essential to meet the complexities of diagnosis and treatment of chronic disease. The community health services of the future will have to be based increasingly on group medical practice in which general physicians and specialists work together to provide maximum continuity and effectiveness of medical service.

The need for continuity of care requires thorough coordination of community services and facilities. Easy and efficient transfer from one type of service to another will be achieved best when the present acute hospital is replaced by an integrated health center which combines at one site and under one administration the facilities for preventive and ambulatory services, acute hospital care, chronic hospital care, nursing home services, coordinated home care, and rehabilitation. 'The trends in this direction are only beginning to become manifest; such integrated facilities need to be developed far more rapidly if the current quantitative and qualitative gaps in the care of the chronically ill are to be filled and if genuine continuity of service is to be attained.

Home nursing services must be closely coordinated with these integrated health centers. The district nursing personnel of health departments and visiting nurse associations should make their headquarters, wherever possible, in the centers serving their districts in order to assure efficient synchronization of home and hospital care.

In the interest of the patient, coordination will have to be achieved not only horizontally, within each community, but also vertically, between smaller and larger communities. Ready access to the highly specialized services of major teaching centers must be realized for patients from small cities, towns, and rural areas to make certain that every individual in a region can benefit from the resources available to residents of large cities. Regionalization of health centers, including a two-way flow of patients to the larger centers and personnel and services to the smaller ones, will need to be brought down from the stratosphere of theory to the solid ground of practical accomplishment.

Since disability presents major problems in chronic disease, rehabilitation services should become an integral part of all community health facilities in order to minimize disability and restore patients insofar as possible to community living. Psychiatric services can no longer be maintained in their present, unmagnificent isolation; they too must become integrated into all general health services and facilities.

Most students of community health service organization would probably agree on this general outline of the future of community health services. What is not quite so clear are the specific ways in which these health services will be organized and the mechanisms to be used in moving toward the general goals. A great deal of experimentation is necessary with new types of services and facilities, new methods of providing care, and new approaches to the realization of health services which are comprehensive, well balanced, and of high quality, and 
which emphasize prevention, rehabilitation, and continuity of care.

\section{Strengths of the 1961 Act}

One of the great strengths of the Community Health Services and Facilities Act of 1961 is that it recognizes the need for such experimentation and provides the financial resources to make it possible. The act increases from $\$ 30$ million to $\$ 50$ million the annual appropriation authorization for Federal matching grants to the States to assist them in establishing and maintaining adequate public health services, and it also authorizes the earmarking of part of the appropriations for specific activities. The funds which would be available to the States can thus be directed toward the establishment and maintenance of programs for improving the scope, quality, and availability of community health services such as those provided in nursing homes, home health care programs, outpatient diagnostic services, and health referral and information centers.

In addition, the act authorizes a new 5-year program of up to $\$ 10$ million annually for special project grants to public and nonprofit organizations for studies, experiments, and demonstrations of new or improved methods of providing out-of-hospital community health services, particularly for the chronically ill and the aged.

The act doubles the annual appropriation authorization for Hill-Burton grants for the construction of public and nonprofit nursing homes. It also liberalizes the eligibility requirements for rehabilitation center construction under the Hill-Burton program. Formerly, to qualify for this Federal aid, a center had to provide, in addition to medical services, three other special services: psychological, social, and vocational. This meant that only a few of the larger centers could qualify. Under the new legislation, centers providing medical services plus one of the other services will be eligible for construction funds. This change will enable many more hospitals, health centers, and other agencies to expand or establish restorative services for the chronically ill or aged.

Finally, the act increases from $\$ 1.2$ million to $\$ 10$ million the annual appropriation ceiling for research, experiments, and demonstrations in utilization of medical facilities, extends eligibility for grants under this program to medical facilities other than hospitals, and authorizes appropriations for grants for the construction and equipment of experimental or demonstration hospitals and other medical facilities.

The Community Health Services and Facilities Act of 1961 is, as written, a very modest proposal. The language of the act, couched in terms of amending various sections of the Public Health Service Act, is hardly that of a magna charta outlining a brave new world of community health services. The sums provided are small when one considers the magnitude of the problems with which the act is concerned.

Nevertheless, the Community Health Services and Facilities Act is, viewed in historical perspective, a major piece of health legislation. Its significance lies not so much in the amount of funds authorized as in the basic recognition that community health services must be reorganized and expanded to solve the problems created by the changing character of disease in the population. It makes a small beginning in providing support for the changes which will take place, but this is a beginning which must inevitably result in much larger programs.

Central to the purpose of the act is the stimulation of community experiments and demonstrations to develop new and improved methods of providing services, both in and out of hospitals, for the chronically ill. The Federal Government has thereby invited health agencies, both public and voluntary, to reexamine their activities, create new approaches, and provide a sound basis for meeting the critical needs in health service organization. The future of community health services has been placed squarely in our hands; we can no longer hide our heads in the sand, pretend that the problems do not exist, or wait for someone else to solve them. Our generation must grapple with the mammoth task of reorienting and reorganizing community health services. Let us make certain that we will not be found wanting either in the quality and inventiveness of our thinking or the boldness and effectiveness of our action. 